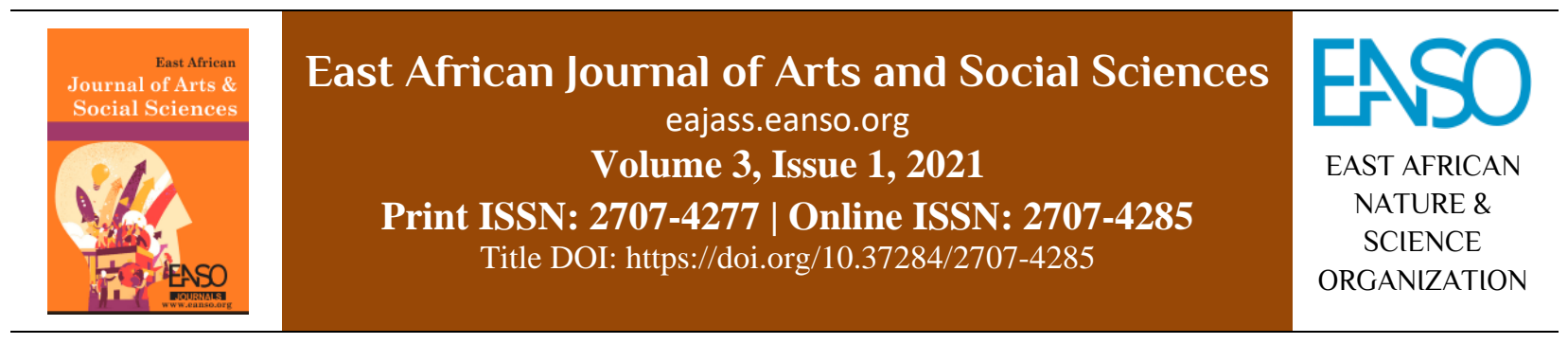

Original Article

\title{
Chicken Delicacy and Chicken-Related Rituals: A Gateway to Understanding the Luhya
}

\author{
Evans Nyongesa Odutsa. \\ ${ }^{1}$ Department of Linguistics, Creative Arts and Film Studies, Moi University. P. O. Box 3900- 30100, Nairobi, Kenya. \\ * Correspondence email: nyongesaevanas@gmail.com.
}

Article DOI: https://doi.org/10.37284/eajass.3.1.325

\section{Date Published: ABSTRACT}

10 May 2021 This article provides a detailed examination of the traditional Luhya people's rituals involving chicken as a delicacy and an element of rituals. The aim of

Keywords: the study was to evaluate the significant place of such rituals in the present-day

Chicken Delicacy, Chicken Rituals,

Gateway,

Luhya Worldview.
Luhya community. Traditionally, chicken served various functions, including settling family disputes, biding grandchildren upon visiting their relatives, and serving the purpose of the traditional ritual. Among the Luhya, a traditional ceremony and celebration cannot be meaningful without people having not only wafted but also tasted the delicacies of chicken. The elements of chicken rituals are based on a study of the chicken and the related rituals among the Bantu-speaking people of Western Kenya and Eastern Uganda in Africa. The study was inspired by the fact that the contemporary cultural context of chicken and rituals has undergone some transformation. Traditional practices were of a particular and rather narrow profile linked to appeasing the dead, source of food, especially ugali and chicken stew, identifying new sites for setting up a home, Olugala, and official inauguration of traditional ceremonies such as circumcision. It is this that has made Luhya to be mostly associated with chicken by other communities in East Africa. Equally, the chicken and rituals among Luhya are linked to the cultural performances and creative arts, which are understood, appreciated, preserved and practiced acceptably by the community hence accelerating the achievement of communal coexistence, and mutual national unity based on sound foundations of diverse cultural identities. The chicken rituals form the basic foundation of studies of the Luhya cultures. Traditional chicken slaughtering practices and their related rituals have become a valuable cultural identity with treasures if closely studied, researched,

82 This work is licensed under a Creative Commons Attribution 4.0 International License. 
theorized and practiced. Therefore, this paper contributes an important avenue for a better understanding of the Luhya traditional culture and people.

\begin{abstract}
APA CITATION
Odutsa, E. N. (2021) Chicken Delicacy and Chicken-Related Rituals: A Gateway to Understanding the Luhya East African Journal of Arts and Social Sciences, 3(1), 82-91. https://doi.org/10.37284/eajass.3.1.325
\end{abstract}

\title{
CHICAGO CITATION
}

Odutsa Evans Nyongesa, 2021. "Chicken Delicacy and Chicken-Related Rituals: A Gateway to Understanding the Luhya". East African Journal of Arts and Social Sciences 3 (1), 82-91. https://doi.org/10.37284/eajass.3.1.325.

HARVARD CITATION

E. N. Odutsa, (2021) "Chicken Delicacy and Chicken-Related Rituals: A Gateway to Understanding the Luhya", East African Journal of Arts and Social Sciences, 3(1), pp. 82-91. doi: 10.37284/eajass.3.1.325.

\section{IEEE CITATION}

Evans E. N., "Chicken Delicacy and Chicken-Related Rituals: A Gateway to Understanding the Luhya", EAJASS, vol. 3, no. 1, pp. 82-91, May. 2021.

\section{MLA CITATION}

Odutsa Evans Nyongesa. "Chicken Delicacy and Chicken-Related Rituals: A Gateway to Understanding the Luhya”. East African Journal of Arts and Social Sciences, Vol. 3, no. 1, May. 2021, pp. 82-91, doi:10.37284/eajass.3.1.325.

\section{INTRODUCTION}

Traditional African practices entail societal beliefs, rituals, taboos and values held by a community. These practices vary from community to community. Various elements of rituals carry symbolic meanings that also reinforce the overall impact of the entire ritual. Among the Luhya people of Kenya, various ritual practices are used to give people a sense of belonging and identity. The term 'Luhya' is an umbrella for various sub-groups residing in western Kenya. Therefore, among the Luhya, rituals cut across all these sub-communities. Among the Luhya cultural practices are male circumcision, naming of the new-borns, traditional official welcome and feasting of the son-in-law at his in-law's homestead (Okhusaba), death rituals, polygamy and marital engagement. In present-day Luhya society, the manner in which each of these cultural practices are conducted has caused some divisions across the sub-tribes. Despite the changes brought about by the forces of post-modernist thinking, such as advances in communication technology, urbanization and globalization, among others, the Luhya people have tried to keep their cultural traditions and practices unchanged. In some cases where modernization has been inevitable, the Luhya have endeavoured to retain the basic components that sealed these rituals, for instance, the place of the chicken and its related rituals (Ingokho ya Mulukha/ingokho ya musango). This paper provides a detailed discussion of the features inherent in the rituals that involve chicken and explores the beliefs and practices concerning gender and the consumption of chicken parts. The aim is to provide a case study and account for the changing nature of the Luhya traditional cultural practices and beliefs. Chicken rituals are all ceremonies that involve the use of chicken and chicken parts as an essential ingredient or element of the entire process of ritual.

\section{Statement of the Problem}

Traditional forms of rituals and ceremonies were accompanied by certain oral-literary performances that had educative and aesthetic values. However, just like other traditional rituals performed among the Luhya, and many other Bantu speakers, traditional ritualistic ceremonies among the Luhya face many challenges brought about by the forces of post-modernity and other aspects of social progress. These forces range from the influx of Christianity and western formal education to globalization and urbanization. These forces of post-modernity have tended to disregard all or some features of the traditional rituals such as chicken ritual practices, considering them as unholy or evil and, or simply as not important for the modern Luhya society. Among

83 This work is licensed under a Creative Commons Attribution 4.0 International License. 
segments of the modern (especially educated Christian) Luhya, there is also the growing view that traditional chicken rituals are outdated, expensive and time-consuming. Under which occasion are the chicken rituals performed and are they still meaningful in today's Luhya Society? If so, what new meanings have these rituals imbibed over the years and what is the significance of such changes to the general understanding of culture among the Luhya people? These are the questions that this paper seeks to answer.

\section{LITERATURE REVIEW}

There is unsubstantial research on the Luhya chicken rituals and the other associated emilukha kia etsingokho (rituals of chicken) as referred to among the Luhya people. However, most writings on Luhya rituals have focused on circumcision, child naming, marriage, deaths among others forgetting the key components that are used to make these rituals meaningful to the community members. Quite a number of such works have been published in daily newspapers and academic journals. Newspaper articles are journalistic in nature and as such, they only report on the ritual ceremonies, their myths about the historical background of these rituals. For instance, the case of the Bukusus circumcision rituals, Embalu or Sikhebo, the incidents when some Bukusu men were forcefully circumcised, the impact of HIV/AIDS on Embalu rituals and the unusual happening of circumcision such as when Sikhebo goes awry, all these incidences have always been captured in the local Kenyan newspapers. Other notable rituals that hardly escape the attention of the Kenyan media personnel are the unique burial rituals of the Bakhibe people, a sub-clan of the Luhya community.

Quite a number of scholars have approached the Luhya rituals differently. For instance, Were (2014) preoccupied himself with the traditional ritual ceremony known as Edurama, highlighting only modern types of circumcision practiced today among the Bukusu and the dramatic elements in Bukusus' Embalu rituals. Were's work does not, however, capture the components that make this ritual authentic, wholesome and functional to its people. How could embalu be meaningful without chicken rituals (engokho ye kumusango)?
Wanyama (2006) examined the relevance of music education in Kenya's 8-4-4 system. He was specifically concerned with finding out the place of traditional African music (taking the case of the Bukusu circumcision songs) within contemporary music training programmes. He pleads to the Ministry of Education to adopt music as an examinable subject hence making learners and teachers give it the desired attention and seriousness it deserves. Even though his findings advocated for music for education purposes, he further recommends folk performances, that is, music, drama and dance, to be integrated into one subject area of arts and culture. His study nonetheless does not highlight the elements of the rituals that constitute the traditional African performances. Therefore, this article seeks to show the place of chicken rituals in present-day Luhya society.

In relation to Wanyama's work, it is worth noting that chicken rituals have inspired some local Luhya musicians such as Vincent Ongidi in his 2009 album, Mama Mulayi (Mum is good). Within this collection, in the song Moya Keingogho nyanga kakhayale (One day chicken feathers shall tell the truth), Ongidi brings hope to the Luhya people in their quest for presidential aspirations. He says that, someday, chicken feather rituals will determine and make their own son or daughter of the land (Luhya) the president of the republic. Ongidi thus uses music to give hope to the Luhya community, through the analogy of the chicken ritual, that by not giving up their quest for the presidential race one day they will rule Kenya. Ongidis's music is specific since it narrows down to certain aspects of the chicken ritual that should eventually help one of the Luhya sons or daughters to rule the nation.

Makwa (2010) has explored musicking and dancing of imbalu circumcision rituals. He demonstrates that such musicking is meant to inspire and reinforce the prosperity of Bagisu's circumcision rituals. He emphasises how the musicology of imbalu aids in the performance of gender among the Bagisu people. His study, being ethnographical, does not capture the usefulness of the chicken in Imbalu rituals, bearing in mind that Bagisu and Bukusu share a lot in common and their circumcision cannot go on without the official opening of the rituals at the Bumutoto grounds in Mbale, Eastern Uganda. It is during the official inauguration of imbalu

84 | This work is licensed under a Creative Commons Attribution 4.0 International License. 
ceremonies at Bumutoto grounds that the chicken rituals are always undertaken to make the male circumcision authentic and all-inclusive to the entire community.

Nyongesa (2019) has examined the changing trends of imbalu rituals among the Bamasaaba of Eastern Uganda. Nyongesa's findings do not provide any details on the chicken ritual undertaken during the inemba stage of imbalu. He neither demonstrates how the chicken rituals are essential during imbalu, especially when the initiates visit the burial grounds of community members to fellowship with the ancestors before undergoing the cut. Therefore, this paper highlights the usefulness of the chicken rituals to the specific cultural practices among the Luhya.

In his recent work, Omukangala (2021) highlights the specific incidences under which chicken rituals are performed and why. Nevertheless, his work focuses only on the Luhya groups residing in Busia County (the Bakhayo, Samia and Marachi). Omukangala's work also sheds light on all Luhya rituals, their significance and their usefulness to the current generation. It documents the authentic Luhya rituals, their usefulness amidst the changing society.

\section{MATERIALS AND METHODS}

The choice of the chicken and the rituals was based on the fact that chicken is the most treasured ritual element and food delicacy among the Luhya of all ages. The research was both qualitative and quantitative in nature. Field research was carried out from June 2020-March 2021. The research was undertaken in Nambale, Funyula and Butula in Busia County. In the regions, the participants were mainly elders and youths who were interviewed. Moreover, in Namusasi (Bumula) in Bungoma County, the researcher identified and interviewed one circumcision surgeon, along with some elders. These were also interviewed before, during and after the chicken and the rituals as undertaken within the circumcision rites. The selected elders, youths and the surgeon provided information on the social and historical background and significance of the chicken and the chicken rituals. The whole process was audio and videotaped, which helped later in analysing the results. It is important to note that besides fieldwork, library research was also carried out to enhance the study outcomes. A review of research works related to the chicken and chicken rituals was also undertaken.

\section{RESULTS AND DISCUSSION}

\section{Luhya and Luhya Sub-clans}

The Luhya (also known as Abaluyia or Luyia) are a group of 19 distinct Bantu tribes in Kenya._The various Luhya groups lack a common origin; they were instead united politically in the mid-20th century (Ember \& Ember, 2003). The Luhya population is estimated at $6,823,842$ people, according to the 2019 census. This number constitutes about $14.35 \%$ of Kenya's total population of 47.6 million. Moreover, the Luhya is the second-largest ethnic group in Kenya (Kenya National Bureau of Statistics, 2011).

The term Luhya refers to both the 19 Luhya tribes and their respective languages collectively called Luhya languages. There are 19 (and by other accounts, 20, when the Suba are included) subtribes that make up the Luhya. Each sub-tribe has a distinct dialect. The word Luhya or Luyia in some of the dialects means "the north", and Abaluhya (Abaluyia) thus means "people from the north". Other translations are "those of the same hearth."

The seventeen most known Luhya sub-tribes are the Bukusu (Aba-Bukusu), Idakho (Av-Idakho), Isukha (Av-Isukha), Kabras (Aba-Kabras), Khayo (AbaKhayo), Kisa (Aba-Kisa), Marachi (Aba-Marachi), Maragoli (Aba-Logoli), Marama (Aba-Marama), Nyala (Aba-Nyala), Nyole (Aba-Nyole), Samia (Aba-Samia), Tachoni (Aba-Tachoni), Tiriki (AbaTiriki), Tsotso (Abatsotso), Wanga (Aba-Wanga) and Batura (Abatura). Bukusu are closely related to the Masaba (or Gisu), whose language is mutually intelligible with Luhya. The Bukusu and the Maragoli are the two largest Luhya sub-tribes.

The principal traditional settlement area of the Luhya is in what was formerly the Western province of Kenya. A substantial number of them permanently settled in the Kitale and Kapsabet areas of the former Rift Valley province. Western Kenya is one of the most densely populated parts of Kenya.

85 This work is licensed under a Creative Commons Attribution 4.0 International License. 


\section{Culture of the Luhya}

Luhya culture is comparable to most Bantu cultures. Polygamy was a common practice in the traditional Luhya society. However, today, it is only practiced by few people, usually, if the man marries under the traditional African or Islamic laws. Conversely, civil marriages (conducted by government authorities) and Christian marriages preclude the possibility of polygamy.

Among the Luhya, about 10 to 15 families traditionally made up a village, headed by a village headman (Omukasa). Oweliguru is a post-colonial title for a village leader, coined from the English word "Crew." Within a family, the man of the home was the ultimate authority, followed by his firstborn son. In a polygamous family, the first wife held the most prestigious position among all women in a homestead.

The first-born son of the first wife was usually the main heir to his father, even if he happened to be younger than his half-brothers from his father's other wives. Daughters had no permanent position in Luhya families as they would eventually be married off to other clans, sub-tribes or even tribes. For this reason, daughters did not inherit property and were excluded from decision-making meetings within the family. Today, however, girls have a right to inherit property, and this right is protected in Kenyan law.

In the Luhya society, children are named after the clan's ancestors, after their grandparents, after events, or the weather. The paternal grandparents take precedence so that the first-born son will usually be named after his paternal grandfather (Kuka or 'Guga' in Maragoli) while the first-born daughter will be named after her paternal grandmother ('Kukhu' or 'Guku' in Maragoli). Subsequent children may be named after maternal grandparents, after significant events, such as weather, seasons, etc. The name Wafula, for example, is given to a boy born during the rainy season (ifula/efula). Wanjala is given to one born during a famine (injala/enjala).

Traditionally, the Luhya practiced arranged marriages. The parents of a boy would approach the parents of a girl to ask for her hand in marriage. If the girl agreed, negotiations for dowry would begin. Typically, this would comprise at most 12 cattle and similar numbers of sheep or goats, to be paid by the groom's parents to the bride's family. Once the dowry was delivered, the girl was fetched by the groom's sisters to begin her new life as a wife. Instances of eloping were and are still common. Young men would elope with willing girls, with negotiations for a dowry to be conducted later. In such cases, the young man would also pay a fine to the parents of the girl. In rare cases abductions were normal, but the young man had to pay a fine. As polygamy was allowed, a middle-aged man would typically have two to three wives.

When a man got very old and handed over the running of his homestead to his sons, the sons would sometimes find a young woman for the old man to marry. Such girls were normally those who could not find men to marry them, usually because they had children out of wedlock. Wife inheritance was and is still also practiced in the Luhya community. A widow would normally be inherited by her husband's brother or cousin. In some cases, the eldest son would inherit his father's widows (though not his own mother).

Modern-day Luhya do not practice some of the traditional customs as most have adopted a Christian way of life. Many present-day Luhya people live in towns and cities for most of their lives and only return to settle in the rural areas after retirement or the death of their parents.

The traditional Luhya also had extensive customs surrounding death. There would be a great celebration at the home of the deceased, with mourning lasting up to forty days. If the deceased was a wealthy or influential man, a big tree would be uprooted and the deceased would be buried there. After the burial, another tree, Mutoto, Mukhuyu or Mukumu (fig tree), would be planted. This was a sacred tree and is found along most Luhya migration paths; it could only be planted by a righteous lady mostly a virgin or a very old lady. Nowadays, mourning takes less time (about one week) and the celebrations are held at the time of burial. "Obukoko" and "Lisabo" are post-burial ceremonies held to complete mourning rites.

86 | This work is licensed under a Creative Commons Attribution 4.0 International License. 
Animal sacrifices were traditionally practiced. There was great fear of the "Abalosi" or "Avaloji" (witches) and "Babini" (wizards). These were "night-runners" who prowled in the nude running from one house to another casting spells.

\section{Significance of the Chicken in Luhya Existence}

Chicken (Gallus gallus domesticus), a subspecies of the red jungle fowl, is a type of domesticated fowl, originally from Asia. The rooster or cock is a term for an adult male chicken. A younger male may be called a cockerel (idaywa); a male that has been castrated is a capon. The adult female bird is called a hen (isenye). "Chicken" was originally a term used only to refer to an immature, or at least young, chicken. However, thanks to its usage on restaurant menus have now become the most common term for the subspecies in general, especially in American English. In older sources, common fowl or domestic fowl were typically used for this purpose. Originally raised for cockfighting or for special ceremonies, chickens were not kept for food. Humans keep chickens primarily as a source of food (consuming both their meat and eggs) and as pets. Chicken for food is known as ingokho yooria/yskhuria. Chicken for rituals and sacrifices is called ingokho ya mulukha/musango.

Chickens are one of the most common and widespread domestic animals, with a total population of 23.7 billion as of 2018, up from more than 19 billion in 2011 (Food and Agricultural Organisation, 2011). There are more chickens in the world than there are any other birds. There are numerous cultural references to chickens - in myth, folklore and religion, and in language and literature.

\section{Traditional Cultural Practices of the Chicken and its Rituals in Luhya}

Among the Luhya, the chicken served (and still serves) as an important delicacy and ritual element in various events as described below.

\section{Setting up of a New Homestead (olugala)}

When the time came for a man to move out of his father's compound and construct his own home elsewhere, Olugala, a cock was used to mark the attendant ceremony. Only married men were eligible to construct Olugala since it was not considered a home unless it had a wife and husband, and children perhaps. The man himself took a young cock yet to start crowing to a place his father had allocated to build his own home in the evening. He would then choose the exact position where he wanted his house to be built and put the cock there. He would then cover the cock using a traditional bucket (Esikono) and go back home. He then returns the following day in the morning to check if the cock was still present. If he found the cock alive, the place was considered safe for human inhabitation. He then went ahead to build his Olugala with the assistance of his clan's men. Chicken and goat were slaughtered for those who came to offer a helping hand and the couple started living in the hut on the very day it was finished. On other hand, if the cock was eaten by the wild animals overnight, the site was considered unsafe. Presumably, staying there would result in deaths, sicknesses and other bad omens. The plans to construct a home in such a site were halted and the process was repeated elsewhere until the cock was found alive the following morning.

\section{Chicken and Burial Rituals}

When the head of the family died in traditional Luhya society, a chicken called ingokho ya Omulukha was used to perform rituals after burials. If the person who had passed away was a male, a cock was used; and if a woman, a hen was used. Unlike how it was done during the preparation of the chickens meant for normal consumption, ingokho ya Omulukha was not slaughtered. After the burial ceremonies, a bonfire, known as amakenga, was lit in the yard to keep mourners warm. An elder from within the clan, preferably a brother to the deceased, was then handed the chicken to perform the ritual. He hit the chicken's head embers repeatedly until it succumbed to the hitting. Hot water was not used to pluck out its feathers; instead, the feathers were left to burn so that the exuding smoke, Omulukha, rose up to the sky. Every part of the chicken that could be consumed by the fire without causing losses was left to burn. Later, the remaining part of the chicken was roasted and shared among all mourners present in the homestead. The ingokho ya Omulukha ceremony was meant to appease the spirit of the dead so that it would not come to haunt relatives.

87 This work is licensed under a Creative Commons Attribution 4.0 International License. 
The ceremony marked the decent send-off in the old Luhya culture.

Additionally, when an adult died while away from home, chicken rituals were performed. When bringing the deceased's body home for interment, the gate or main entrance was not used. The body was brought in through the back of the house; a new entrance was created by elders. Once the body was in the house, the new gate was closed. This closing was accompanied by chicken rituals. The chicken was slaughtered for this purpose. The slaughtered chicken was referred to as Esibaanga. Just like Ingokho ya Omulukha, Esibaanga was thought to pacify the deceased. It also kept bad spirits away from the family members and ensured that such a way death did not recur in the family.

Traditionally, among the Luhya, the chicken and related rituals were also useful in the preparation of the final resting place of the deceased (gravesite). After digging the grave, the gravediggers were given the chicken to roast at night. This chicken was consumed at night by the gravediggers. If not roasted, it was cooked and consumed by the gravediggers at the gravesite.

Similarly, before destroying a hut/house built by the deceased, the chicken rituals were performed to appease the spirits of the dead. Equally, it also served the purpose of inviting the deceased to take part in the rituals. A red cock was slaughtered at the head-side of the deceased's grave. It was roasted and consumed in the hut belonging to the deceased. In some other clans of Luhya, the chicken was always roasted and consumed at the gravesite. After that, the deceased's hut or house was destroyed.

\section{Chicken's Spirits Rituals}

In African traditional societies, spirits were thought to have the power to control the living. The dead and the living were in one way linked, so that the dead could still appear and deliver messages to the living, good or bad. Some dead relatives were thus thought capable of turning into very terrifying spirits and terrorising the living both at night and daytime. Such ghosts were stopped or prevented by diviners or sorcerers through chicken rituals. Today, the Luhya sub-tribes still use chicken to bar bad spirits from disturbing the living.
In most cases, black chickens were never used for the purposes like welcoming a new-borns, visitors or gifting grandchildren. Such chickens were believed to bring darkness (Omwirima) into the lives of those who received them. Even though family members could still feast on them, black chickens were frequently used to either curse or cleanse those who had violated some taboos. Other black domestic animals were also used depending on the magnitude of the matter at hand. However, the black chicken was the most convenient since nearly every family had one such chicken. This way of thinking also informed why black cattle were traditionally never acceptable for dowry.

There was also chicken with ruffled feathers called ingokho ya Namasasabare, which was very instrumental among the Samia people. Regardless of its colour, ingokho ya Namasasabare was largely used for sorcery and was never slaughtered for guests, especially in-laws. The one without feathers around the neck, Nagosi Mbako, was also used for similar practices were applicable. Nagubende, a chicken without (tail), played a pivotal role in rituals amongst the Luhya. First, when a marriage failed and the son-in-law kept coming for his cattle brought as dowry back (the Luhya culture permitted one to do so and for one reason or another could not be refunded), the solution was to slaughter for him Nagubende. He would then never come back again after eating the chicken. Nonetheless, many sons-inlaw hardly accepted food from the in-laws for fear of being blackmailed through such tricks. Secondly, for families that were denied peace by a family member that had passed away, Nagubende was the remedy. Sorcerers or diviners were invited by the troubled family at night to perform the chicken rituals. Nagubende was slaughtered and its beak (mouth) opened for every family to spit into it before some medicines were added and sealed to bind the spirits. The chicken head was then buried somewhere outside the compound. None of the family members was allowed to eat the chicken used for this particular ritual. More often than not, it was thrown into the bush for the wild animals to eat, albeit some sorcerers took it along with them to go and consume it. A shaky eggy that failed to hatch after 21 days was also very instrumental sorcery and witchcraft that involved the use of thunder and lightning.

88 This work is licensed under a Creative Commons Attribution 4.0 International License. 


\section{Chicken for Devine Intervention}

Before the Europeans brought Christianity into the Luhya villages and used it to demean and scold the beautiful ways of life, the Luhya used to have a special place of worship, either under a tree or shrine. A normal white chicken was believed to bring light or hope to the family. They would take a white chicken to their places of worship and pluck four feathers and pegged one at each corner of the shrine. They then plucked one feather and have it pinned in the middle. The traditional Luhya did this every morning before they made their morning prayers, interceding on behalf of the family. The ritual was called Omweera. The white chicken was used because the supernatural being was believed to be as white as a snow. The Supreme Being was referred to as Were Achari Khagaba in Samia. White chicks were also given to the grandchildren regularly whenever they went to visit their grandmothers. They were thought to brighten the future of the grandchildren and keep spirits of darkness at bay.

\section{Chicken Rituals for Welcoming Son-in-law (okhusaaba)}

Traditionally, the son-in-law was not allowed to visit the girl's homestead impromptu. A special ceremony was conducted to allow the son-in-law to visit the family, eat and dine. This ceremony was preceded by the payment of dowry. Even after dowry payment, the elders were always given a chicken to be consumed by the son-in-law with his brothers, fathers and grandfathers. Commonly referred to as Okhusaaba, this chicken marked the great connection between the son-in-law and his inlaws. Without this ritual, the son-in-law was not allowed to eat meals prepared in the kitchen belonging to the mother-in-law, nor any meals prepared by the mother-in-law. If a son-in-law happened to visit the in-law's family perhaps by invitation or in attendance of an event, his meals were prepared by the mother-in-law but not in the mother-in-law's kitchen.

During such ceremonies, there were three important meals that the son-in-law ate together with those accompanying him. In each set of meals, there had to be a chicken. The chickens were always cocks and hens. Therefore, every family had to keep special chicken, cocks (idaywa), that were slaughtered and prepared specifically for the son-inlaw. The son-in-law was also gifted with a chicken when he left after the ceremony. Before this special cock was slaughtered, the eldest brother-in-law was asked to give it to the son-in-law to check if it was strong, worthy to be consumed by him. If the sonin-law was not convinced, the family of the girl was forced to look for the strongest cock and present it to him to ascertain its strength before slaughtering. Upon accepting it, the cock was slaughtered and prepared under the watch of the sister to the son-inlaw. This chicken was referred to as Ingokho ya Mukhwe (chicken for son-in-law). Its preparation was uniquely done in a traditional pot called Esiika. It was also prepared full except without the intestines. Before the son-in-law left the in-laws homestead, it was again the chicken that dictated the time he had to leave. Traditionally, the son-in-law was only allowed to leave before the first cock crowed. And he opted to spend the night, the sonin-law was taken outside the homestead till the first the cock had crowed. This was when he was then allowed back into the homestead. The first cockcrow signified the beginning of a new day. Moreover, the cock crowing while he was outside meant that the son-in-law had not spent in his mother-in-law's homestead, as this was considered taboo.

\section{Chicken's Rituals for Circumcision}

Among the Luhya, the circumcision ritual plays a very significant role in the life of an individual. Circumcision is a moment in which society ensures that the young generation has a tight grip on their society. It also ensures the community develops a sense of confidence that they have in themselves through its traditional practices such as initiation rituals. Since every member of the community is practically involved in the ceremony, the ritual serves to create a sense of unity. The meaningfulness of the circumcision rituals is marked across the various stages with the chicken rituals. For instance, during the official opening of imbalu rituals among the Bukusu, a sub-community of Luhya, the chickens are used for various circumcision rituals. They are slaughtered and their blood smeared on the circumcising knives to mark the beginning of the circumcision rituals. Their blood is also used for libation as a way of inviting

89 | This work is licensed under a Creative Commons Attribution 4.0 International License. 
the ancestors to bless and take part in the rituals. In some families, chickens are offered purposely as a sacrifice to the dead. The circumcisers, after circumcising, are always gifted with the special chicks that they rear in their homes. During Khuchukhila stage of imbalu, the chicken is always gifted to the initiate encouraging him to stand the ordeal courageously. After the circumcision, the circumcisers use the chicken still for the purpose of Khubiita the newly initiate by teasing and encouraging him hence weaning him to adulthood. It is still chicken that the initiated are encouraged to consume.

\section{Chicken Rituals Stereotypes}

Among most of the traditional Luhya sub-tribes, chicken meat was only meant for men. In some of the tribes, certain parts of the chicken, such as the Gizzard (imondo), was to be only consumed by the eldest man in the house and never to be shared. Chicken was also slaughtered for a specific purpose. Upon grandchildren visiting their grandparents, the male grandchildren were gifted with young cocks while girls were gifted with hens. These chickens that were gifted were of different colours, the only exemption being those of black and red colours as well as the chicken with ruffled feathers since they were associated with various societal stereotypes that could harm children. Chicken eggs were also prepared for the visitors and even given as gifts to grandchildren whenever they visited their grandparents and relatives. Today, society has lost its moral values since it is believed that the chickens are slaughtered randomly and consumed by all genders. Arguably, some elders believe that such random and reckless consumption of chicken explains why there are high death rates among girls and young women across Luhya land.

The traditional Luhya believed that chicken was never meant for women. As such, women would prepare the chicken and serve their husbands without even tasting it. Traditionally among the Abakhayo, Batsotso, Tiriki, Batura, Samia and Marachi (sub-communities of Luhya), women were not allowed to serve their husbands with delicacies. Rather they could simply prepare and take it to their husband to serve themselves. This explains why most great grandmothers today in Luhya land do not eat chicken since society had attached negative stereotypes that forbade women from eating the chicken. Across the Luhya community today, these negative stereotypes have evolved into different acts forbidding women not to eat the gizzard. Whenever chicken is slaughtered in Luhya, the gizzard is only meant for the head of the family (husband); in his absentia, the first-born son was given the gizzard to eat. In the event the firstborn is absent, the secondborn son is the one to eat the gizzard. If there is no male person in the family, it is always advised that the gizzard be given to the eldest male in the neighbouring homestead. Society has thus attached so many stereotypes that it has discouraged quite a number of Luhya girls from eating the gizzard.

There are more stereotypes around the chicken among the Luhya, and these stereotypes varied in some degree across the sub-tribes. Another stereotype, for instance, held that a hen crowing was a bad omen and such a hen was to be slaughtered immediately. Similarly, when a cock tried to mount another cock, it was also considered a bad omen. Moreover, when a cock crowed in the middle of the night, instead of at dawn, it was thought to be a bad omen and the cock was to be slaughtered immediately. It was further considered a bad omen for a cock to lay an egg, such a cock was to be slaughtered immediately.

\section{CONCLUSION}

This paper has explored the cultural practices surrounding the chicken rituals among the Luhya people of Kenya. The point of departure of the article was the need to highlight the various perspectives from which the world has perceived the Luhya practices that are associated with the chicken rituals. The discussion showed that the chicken rituals marked various ceremonies undertaken in the Luhya society. This explains why the chicken remains an important delicacy as well as a ritual element. However, the study also showed that there are certain cultural beliefs and practices about chicken that may have no value to present-day Luhya. Among these is the symbolic value of a black or red chicken. Then there is also the notion that women should not consume chicken or parts of the chicken. One positive contribution of beliefs about chicken that is notable among the Luhya is that chicken meat and eggs provide a stable diet that is good for the family. Moreover, for their love of

90 This work is licensed under a Creative Commons Attribution 4.0 International License. 
chicken, the Luhya also find a means to sustain themselves economically by raring chicken. I recommend that a similar study be carried out

\section{REFERENCES}

Ember, C. R., \& Ember, M. (2003). Encyclopaedia of Sex and Gender. New York: Springer.

Food and Agricultural Organisation (2011, July 27). Global Livestock Counts: Counting Chicken. The Economist. Retrieved from https://www.ec onomist.com/graphic- detail/2011/07/27/counti ng-chickens

Kenya National Bureau of Statistics (2011). Population and Housing Census. Retrieved from https://web.archive.org/web/20110712000136/h ttp://www.knbs.or.ke/censusethnic.php

Makwa, D. (2010). Musicking and Dancing Imbalu Circumcision Ritual (Khushina Imbalu): Performing Gender among the Bagisu of Eastern Uganda (Master's Theses). Makerere University, Kampala. focusing on the principal animals for rituals in other communities and rituals associated with the other domestic animals and birds.

Nyongesa, E. O. (2019). Impact of Post-Modernist Trends on the Practice of Imbalu Initiation Rituals among the Bagisu of Eastern Uganda. Scholars Journal of Arts, Humanities and Social Sciences, 7(8), 587-596.

Omukangala, J. B. (2021). Torn Between. African Ink Publishers.

Ongidi, V. (2009). Moya Kiengokho [Song]. In Mama Mulayi [Album]. Vincent Ongidi.

Wanyama, M. N. (2006). Music Education: An Unexploited Goldmine in Kenya. In C. Chelcy \& D. Rohwer (Eds.), Proceedings of Music and Lifelong Learning Symposium, April 14-16, 2005. University of Wisconsin-Madison, U.S.A.

Were, W. (2014). A Traditional Ritual Ceremony as Edurama: A Case Study of Imbalu Ritual among the Bukusu of Western Kenya (PhD Thesis). Kenyatta University, Nairobi.

91 This work is licensed under a Creative Commons Attribution 4.0 International License. 